\title{
The Queen Bees and the Women's Team - \\ A contextual examination of enmity and friendship between military women
}

\section{By Nina Rones and Frank BrundtLand STEDer}

\begin{abstract}
In several studies of women in the Norwegian Armed Forces, we have found an assertion that female groups are so riddled with conflicts and enmity that it is preferable to keep women few in number and mixed up with men, even in dormitories (Hellum 2014; Lilleaas and Ellingsen 2014; Rones 2015). Yet, when the Norwegian Special Operations Command (NORSOC) organized an all-female Special Reconnaissance Platoon, the NORSOC leadership would conclude that they had seen "almost disappointingly little of the conflicts that allegedly should occur in groups of females" (Rones and Steder 2017). Accordingly, this article will critically explore the assertion that women are often so quarrelsome that it is preferable to keep them few in number and mixed with men $24 / 7$.

It will be argued that women's alleged tendency towards enmity is a myth that is made 'true' by 'queen bee behavior'. Queen bee behavior is seen as an act of recognition, whereby women comply with existing gender stereotypes, evaluate women negatively, but set themselves apart from the category of 'women' as someone who fits better with men, i.e. a performance of complicit masculinity. It is further argued that queen bee behavior is a response to the social-identity threat women experience when they enter a unit in which their gender has a low reputation and status, and where it is expected that a woman should fit seamlessly in as one of the guys, and accordingly have to make a symbolic 'change of gender'.
\end{abstract}

\section{KEYWORDS}

military women, gender stereotypes, queen bee response, cohesion, equality, equivalence

Nina Rones and Frank Brundtland Steder 


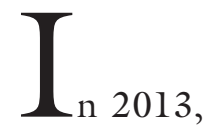

the Norwegian Special Operations Command (NORSOC) came up with the idea of organizing an all-female Special Reconnaissance Platoon. The NORSOC leadership was, however, warned against doing so, since collecting many women in one place would allegedly result in the cat fights one had 'learned to expect from all-female dormitories'. The warning came especially from military women and with reference to research on military culture that promoted all-encompassing integration as an important tool to obtain gender equality. This literature was based on the claim from informants that gender-mixed dormitories eased the negative consequences that would result "if women become too numerous or live too close to each other" (Lilleaas and Ellingsen, 2014, 53). The all-female platoon was nevertheless organized and, after two years' experience, the NORSOC leadership would conclude that they had seen "almost disappointingly little" of the conflicts that allegedly should occur in allwomen groups (Rones and Steder 2017, 76).

Based on findings from the all-female platoon and other qualitative case studies of women in the Norwegian Armed Forces (Bjerke and Rones 2017; Hellum 2014; 2016; Lilleaas and Ellingsen 2014; Rones 2015), this article asks the question: why is it claimed that women are often so hostile towards each other that that it is preferable to keep them few in number and mixed with men 24/7? It will be argued that women's alleged tendency towards gossiping, drama and conflict-making is a myth that is made 'true' by 'queen bee behavior' that follows the social-identity threat women experience when they enter a unit in which their gender has a low reputation and status. In an effort to be accepted as 'one of the guys' in such a culture, 'the queen bee' will typically disparage other women, and keep a distance from them by emphasizing how she herself is different from other women and accordingly fits better with men (she is more like a man) (see Derks et al. 201la; Derks et al. 2016). In her struggle for recognition, 'the queen bee' will also often deny that gender discrimination exists. Queen bee behavior is a problem because gender stereotypical views expressed by women contribute to a powerful legitimization of gender discrimination. In addition, queen bee behavior seems to keep women in a weak position by perpetuating the myth that women are each other's worst enemies, and accordingly should be kept few in number in the armed forces and separated from each other.

The organizational psychologists Derks and colleagues (2011a; 2016) sees 'queen bee behavior' as a response to the sociocontextual situation these women have entered, rather than an inherent personality trait. Accordingly, it is important to understand the contextual situation in which queen bee behavior is encouraged, and in which it is hampered. The purpose of this article is therefore to explore the context, including gender ideologies and views on fairness, which may have hampered queen bee behavior in the little group of women who were admitted to the all-female training program organized by and located in NORSOC's male-dominated Training Wing. This will be done by comparing the NORSOC context with the context in a gender-mixed training program, where a high level of behavior characteristic of the queen bee response was observed, i.e. Rones's (2015) ethnographic study of the Army's Non-Commissioned Officer Candidates School (ANCOCS). 


\section{MYTHS OF CONFLICTS AND COHESION CAUSED BY GENDER COMPOSITION}

The narrative of quarrelsome women became particularly evident in a study on military masculinity-culture by the sociologists Lilleaas and Ellingsen from the University of Oslo's centre for gender research (Lilleaas and Ellingsen 2014, translated into English in Ellingsen and Lilleaas 2017). They had carried out a comparative case study in a large Navy camp where men and women had separate rooms, and a smaller Army camp where men and women bunked together. In the Navy camp, informants reported that the women's rooms were riddled with conflicts, backstabbing, and cliques (Ellingsen and Lilleaas 2017, 104108). The women in the Army camp depicted purely female cultures as a 'horror story' characterized by social drama and rivalry. They claimed that the gender-mixed rooms helped to integrate them as 'one of the boys', and prevented the type of cliquey atmosphere and female gossiping that would normally be expected among women (Ellingsen and Lilleaas 2017, 7880 ).

Following Lilleaas and Ellingsen's (2014) study, the Norwegian Defence Research Establishment's anthropologist Nina Hellum scrutinized the gender-mixed rooms in two different Army camps. Like Lilleaas and Ellingsen (2014), Hellum (2014) found that both men and women thought that female groups and rooms were characterized by drama and conflicts. Accordingly, women preferred to live with men in mixed rooms, and men also thought that quarrelsome women were better off in gender-mixed rooms (pp. 1820). Moreover, men claimed that the mixed rooms diminished the vulgar and abrasive culture that often could occur among men, since they behaved better with women present.

In a later study of the Norwegian Air and Missile Defence Battalions' experiment of a 50/50 distribution of conscripted men and women, Hellum (2016) finds that the "myths of the all-female rooms as riddled with drama" still circulate among officers and soldiers (p. 32), but that the notion that more women also means more drama doesn't apply in this case. Hellum explains the latter with reference to Rosabeth Moss Kanter's well-known study of men and women in the corporation (1977), and her theory that a minority will no longer be treated as tokens when they reach a critical mass that is assumed to be over 15-20 per cent. Although more women meant a tendency towards gendered clique formation, the soldiers believed that gender-mixed rooms slowed this tendency down.

In contrast to these positive observations regarding the mixed rooms, Rones's (2015) ANCOCS study reports from an educational platoon where female officer candidates who lived in gender-mixed rooms had problems getting along and expressed quite hostile attitudes towards each other (pp. 195-205 and 270-273). In this platoon (in the Northern Brigades Medical Battalion), there was a 50/50 distribution of men and women, demonstrating that Kanter's theory of critical mass does not always apply. The actors themselves believed that it was the high proportion of women that affected the culture in a negative way (pp. 196-206). Moreover, female officers and candidates at both the ANCOCS headquarters and in the other educational platoons where there were very few women $(<3)$, were sceptical about an increased number of women in the military. They believed this would result in increased conflicts and a culture of female scheming. The female officers legitimized their scepticism towards more women by pointing out: "Historically, we know that all the conflicts are in the girls' rooms", contending that "it has something to do with how women are" (Rones 2015, 271-273).

Both Lilleaas and Ellingsen (2014) and Hellum $(2014 ; 2016)$ point out that allwomen rooms are not always riddled with 
conflict, and mixed rooms are not entirely free of negative events. Nevertheless, they assign several positive observations to the gender-mixed rooms. In addition to less gossiping among women, this includes less gender stereotypical behavior, less fraternization and sexual harassment, as well as increased team cohesion, respect, tolerance and non-sexual camaraderie across genders. They conclude that mixed rooms have facilitated an intense exposure to the opposite gender, which in turn has made gender insignificant. The argument is based on immigration research (in particular, Thomas Pettigrew's inter-group contact theory) that postulates that increased exposure to a minority (in this case. women) will decrease prejudice, stereotypes and tensions. These results gained tremendous international attention and an all-encompassing gendermixed existence seem to have been promoted as an important tool to ease the integration of female soldiers into the Norwegian Armed Forces (see Rones 2017).

Given that single-sex group, or more especially the all-male group, has been considered crucial to avoid (jealousy-)conflicts and maintain concord and cohesion in the US and UK military debate (Kronsell 2012; Mackenzie 2015; Simons 2000; 2014 ) it seems a bit peculiar that a $24 / 7$ gender mix is believed to reduce gender-related conflicts and promote cohesion in the Norwegian Armed Forces. Cohesion refers to the ties that bind soldiers together, and the issue has been more or less absent in the debate on gender in the Norwegian Armed Forces. This may be explained both by different traditions and ideologies regarding gender equality and by the Norwegian defense discourse that has put more emphasis on the individual soldier and his/her physical achievements than the units and how they can be bound together (Ulriksen 2002).

In the US, however, cohesion, or 'the band of brothers', has been regarded as decisive for soldiers' motivation and willing- ness to stay behind and fight with their own lives at stake, ever since Samuel Stouffer and his research group conducted 500,000 interviews with soldiers who had been fighting during World War II. They found that neither patriotism nor ideology lies behind a soldier's combat discipline. Instead it was a desire to protect their comrades and keep their own unit alive, prove that they were men, and achieve promotion while doing so (Ryan 2010; RAND 2010). The study did not actually explore what really caused the desire to protect their comrades. Yet, many have suggested that homogeneity, i.e. social identification and sameness, is the key to creating the important 'band of brothers', while heterogeneity, especially with regard to sexuality and gender, is believed to be a threat to cohesion. This assumption has lain at the heart of the US ban on women and homosexuals in combat units (King 2013; 2015; 2017; Kronsell 2012; Mackenzie 2015; RAND 2010; Titunik 2000) For instance, Professor Anna Simons, who is considered a leading researcher in Special Forces theory, has argued that opening up combat units to women will create a dangerous dynamic and an internal competition (over the women) that will ultimately kill cohesion (Simons 2000; 2014). Mackenzie (2015) argues, however, that 'the band of brothers' is a military myth that is used to justify the politics of combat exclusion by conveying the 'truth' that all-male units are more capable of accomplishing the military mission and maintaining combat discipline than mixed-gender units.

Newer research on team cohesion in the military (King 2013; 2015; 2017) has also shown that the ability to perform the task with professionalism and the sense of achievement resulting from successful performance seem to be more important for establishing unity and cohesiveness than identity-category, personal ties, camaraderie and brotherhood. As a result, military sociologists have argued that it is adequate 
training of the soldiers, which ensures their ability to perform well and succeed, that is the critical backbone of strong unit/team cohesion, not gender homogeneity or sexual homogeneity (see Ben-Ari et al. 2010; King 2013; 2015; 2017).

So, in sum, while the US has cultivated the belief that single-sex groups (in the form of all males) are crucial to maintain harmony and avoid conflicts among soldiers, it seems to be a belief in the Norwegian Armed Forces that having many women together in a single-sex situation will result in disharmony and quarrels. It is against this background that we are interested in exploring the claim that women, unlike men, are so hostile towards each other that it is difficult for them to interact harmoniously in single-sex units.

We will argue that the myth of quarrelsome women results from 'queen bee behaviour' that is encouraged in a misogynist context where the male is the norm and the women must symbolically 'change gender' to become accepted as one of the guys, i.e. assimilation, not integration. The article will also pay attention to the limited possibility of obtaining gender equality and avoiding gender-related problems through a particular group composition based on social-identity categories. We also hope the article will remind researchers to evaluate critically to what degree their use of informant-assertions can come to make the research-field's myths into 'scientific facts'.

\section{QUEEN BEE BEHAVIOR}

\section{- AN ACT OF RECOGNITION}

The queen bee concept is used within organizational physiology and seeks to describe an observed behavior whereby women fulfill their career aspirations in male-dominated work environments by dissociating themselves from the identity-category of 'women'. This is for instance done by disparaging typical 'womanish behavior' and emphasizing how they themselves differ from other women (Derks et al. 2016). As such, the queen bee concept seeks to describe a woman who joins a male-dominated environment as one of the guys.

The queen bee concept originates from Staines, Travis and Jayerante (1974), who used the label 'queen bee syndrome' to explain the observation that some female leaders who had been individually successful in male-dominated work environments (business/corporation) could be more critical of their female subordinates and impose stricter demands on them than on their male subordinates. Moreover, these women were likely to actively oppose the women's movement, as well as denying that gender discrimination may still exist.

The label 'queen bee syndrome' came under critique, among other reasons because it led to the assumption that hostile behavior towards other women was inherent in the personalities of successful career women. Moreover, discussions of the queen bee phenomenon, especially in the popular media, concluded from these findings that women were their own worst enemies, and that women themselves were an important cause of gender discrimination. The assumptions also led to research that tried to find out who 'the queen bees' were, looking for stable personality traits to explain their misogynist behavior (see Derks et al. 2011b).

Others, however, have sought to examine organizational conditions that foster queen bee behavior, suggesting that the observed behavior is a response to the socio-contextual situation these women have entered, rather than a syndrome or an inherent personality trait (Derks et al. 2011b; 2016). One example is the organizational psychologist Ellemers (2001), who was the first to describe the queen bee phenomenon as a response to the social-identity threat women experience in organizations in which their gender is devalued or has a low reputation and status. This view was later substantiated by her colleagues at 
Utrecht University (Derks et al. 2016; Derks et al. 201la; Derks et al. 2011b). These authors accordingly present a more nuanced view of the popular idea that women are their own worst enemies, and as such are more inclined than men to undermine each other.

In more detail, Derks and colleagues have argued that women who enter environments with a high degree of gender prejudice and discrimination against women are negatively affected in their professional/personal identity. One way by which these women resist the disadvantage of belonging to a devalued group is by dissociating themselves from that group, i.e. from women. Accordingly, the women may comply with existing gender stereotypes, but set themselves apart from the group 'women' in an attempt to prevent others from evaluating them on the basis of their gender. These women can say, 'Women are less career-oriented than men, but $I \mathrm{am}$, by exception, very career oriented and fit better with the guys'. Derks and colleagues refer to this behavior as 'self-group distancing', i.e. a coping response and a strategy that can successfully be used to improve the individual woman's personal career outcomes. However, these women's coping strategy does nothing to improve the standing of women as a group or category. Instead, the queen bee response is detrimental to the reputation of other women. The queen bee behavior is thus seen as a pervasive dynamic in which women contribute to perpetuating and legitimizing the current gender hierarchy as well as the negative stereotyping of their own gender (Derks et al. 2016).

By looking to Pierre Bourdieu, we believe that the queen bee response can be understood as an act of recognition, and an effect of symbolic violence. Symbolic violence can be understood as the values, ideals, and ideas a (historical and/or present) ruling group has imposed onto subordinated groups (and even later generations) by the use of symbols and symbolical acts which communicate recognition and misrecognition. In turn, the symbols and symbolical acts communicates which persons and behavior are of high status and value, and which are not. Symbolic violence is thus a soft power that imposes on men and women tacit ideas of what they 'must' do in order to gain recognition (e.g. be accepted as 'one of the guys'), and in particular to avoid misrecognition. Accordingly, symbolic violence is exercised upon the subordinated groups/persons with their complicity. This is how Bourdieu explains the subordinated group's paradoxical submission to the established order and the dominant group's interests (Bourdieu 1998, 1-2; Bourdieu and Wacquant 1992, 167), and the queen bee response seems to be an example of women's paradoxical submission to masculine domination. In Connell's $(2005,79-80)$ sketch of a gender hierarchy, the queen bee behaviour can, in our opinion, be understood as a form of complicit masculinity, performed by women. That is the form of masculinity many people $d o$ in their struggle to live up to hegemonic masculinity, i.e. a normative ideal that men, and some women, are encouraged to emulate.

According to Enloe (2000), compliance is a key to the maintenance of the military as a patriarchal institution, and we believe the queen bee response, as an act of recognition and compliance/complicit masculinity, contributes to the reproduction of the military field's traditional valuation criteria and ideas on gender. As such, the 'queen bees' help to justify an order where both women and so-called feminine behavior are seen as less important and valuable than men and so-called masculine behavior. That is why it is important to better understand the contextual situations where the queen bee behavior is encouraged or hampered. 


\section{METHOD}

This article is based on a targeted and explorative comparison of contextual issues that may resulted in the observation of, respectively, a hostile and a friendly relationship among the women in two of our previous studies, i.e. 1) Rones's (2015) study of the Army's gender-mixed NCO-Candidate School (ANCOCS) 1 and 2) Rones and Steders's (2017) study of the NORSOC all-female Special Reconnaissance Platoon. ${ }^{2}$

Both the previous studies were based on an inductive content analysis of ethnographic material in the qualitative data analysis software MaxQda 11. The way that the codes and categories were developed was inspired by Charmaz's (2006) suggestion for doing grounded theory. That means that content in each meaningful segment of the data was summarized in a short sentence (i.e. a code), and these sentences were then grouped/categorized in topics that were summarized with a new sentence/code. This resulted in a hierarchical system of short sentences/code-words that summarized the content of the material. There was a striking difference in the summarizing codes and categories that were developed from the two datasets regarding the relationship between men and women, as well as between women themselves.

Regarding the relationships between women, codes developed from the ANCOCS material were for example 'power relations and hierarchy struggles', 'competition', 'conflict', 'girl-gangs struggle to get along', 'prefer to be the only woman' and 'it's so tiresome with other women'. Examples of codes developed from the NORSOC material were 'mutual admiration', 'good friendship', 'social support' and 'couldn't imagine being the only woman'.

Since the findings on the soldiers' relationships were so different in the two studies in spite of them being based on the same methodical approach, we decided to systematically compare the two coded and categorized datasets. Since the results in addition stood in contrast to the expectation that should follow from the previous described claims (findings) regarding the effect of gender-mixed and all-female units (Hellum 2014; 2016; Lilleaas and Ellingsen 2014; see also Rones 2017), we suggested that it was different contextual issues that could have caused conflicts in the gender-mixed case and cohesion in the gender-segregated case. Therefore, we sough explicitly to identify contextual issues other than gender composition when we compared the two datasets. How the contexts may have contributed to the different relationships between the group of men and the group of women has already been presented and discussed in a previous article (Rones 2017). Regarding the relationship among the women, we identified contextual differences that could be grouped into five themes that we will present in this article: i.e. 1) uniformity and usability for everything vs diversity and specialization as an ideal; 2) selection based on performance of behaviour classified as masculine vs feminine; 3 ) the opportunity to be one of the guys vs one of the girls; 4) gendered vs non-gendered division of the internal labour; and 5) identity-threat for men and women vs unique and attractive status for both men and women.

Since this article is based on a comparison of findings and contextual issues from previous studies, we will provide the reader with references to the pages in the publications where the different topics have been described earlier. The aim of this article is to use the previous studies to explore the reason why we, and other researchers who have studied women in the military, have found the assertion that women are so quarrelsome that it is preferable to keep them few in number and mixed with men $24 / 7$. As mentioned, we believe that this is a myth that is made true by the 'queen bee response' that follows from a context such as the one we observed in the ANCOCS 
case, and that is hampered by the contrasting context in NORSOC.

\section{THE QUEEN BEES AND THE WOMEN'S TEAM: A CONTEXTUAL EXAMINATION}

The relations between women at the ANCOCS were characterized by hierarchical struggle, conflicts, irritation and jealousy (Rones 2015, 195-205 and 270-273). Most of the women were of the opinion that having a lot of women resulted in backbiting, plotting, drama, disputes and scheming. Some women asked 'why the hell' some women had been selected, and argued that the other women in their unit were annoying, tiresome, pushy, ill-tempered, competitive, attention-seeking, unfit, and even too ambitious or not ambitious enough. These opinions about other women can be seen as examples of selfgroup distancing, i.e. according to Derks et al. (2011a; 2011b; 2016) behavior that results from the social-identity threat women experience in organizations in which their gender is devalued and has a low status.

The women also spoke about an all-embracing competition (e.g. who was first in bed and first to get up), characterized by malicious pleasure and laughing and gloating over each other's failings, as this quote exemplifies:

I think there are many [of the women in the platoon] who are so reckless. They hope that those they do not like will not succeed [...] If someone is a bit off track: "Ha-ha! Cool!" In particular there are some of the girls that really like competition $[\ldots]$ they are more like: "We have to conquer! Now it is a competition and we will win even if it has to be blood, sweat and tears!" It is a rather hotheaded atmosphere. I think it's funny when they fail, because they become very sulky and sour for days after it. It is very fun (Female NCO-candidate, Rones 2015, 199).

In addition, many ANCOCS women fierce- ly opposed any form of affirmative action, such as quotas, special treatment, and lower physical requirements for women. Instead, they required both themselves and the other women to prove themselves to be of a sufficiently high standard, in particular at physical tests (Rones 2015, 3 and 210218). It is likely that this is something these women do as an act of recognition, because they think it will increase their individual status and career outcome. It can further be argued that these findings describe how women comply with the premises and norms set for and by the dominant group, i.e. men. When they advocate for the importance of masculine physical capital, they also contribute to the reproduction of the dominant group's prerogatives and traditional value criteria, even though it helps to make women - themselves - less valuable in the field. This can be understood as a paradoxical effect of symbolic violence (incorporating ideas of what they 'must' do in order to gain recognition) and a classic queen bee response.

Turning to NORSOC, the leaders said that there had been a "surprisingly" peaceful environment between the women in the all-female platoon, and that they cooperated well and supported and helped each other (Rones and Steder 2017, 76). The women themselves describe good friendships with mutual admiration and support. On the question what has been the best experience of the year in the all-female platoon, it is precisely the unity among the women in the platoon that is mentioned (pp. 77-78). Stories about harsh competition among the women are absent in these interviews. Instead, many of the women emphasize a sense of achievement in addition to strong friendship:

[The best has been] All the exercises, the sense of achievement, the unity with the girls, which have only become stronger and stronger. Created new ties with new people, with people you might never have hung with 
in civilian life. [...] you live so closely, you shower together, you sleep side by side, you eat together, you do everything. In the end, you get a really close bond and you are really fond of everyone. Now, we are really the best friends ever, you see - who you never want to lose contact with. [...] It's a very special relationship that you will never experience with anyone else

(Soldier in the all-female platoon, Rones and Steder 2017, 77).

So, what was the contextual situation that may have encouraged queen bee behavior in the ANCOCS case and may have hampered it in the NORSOC case where a little group of women were admitted to 'a special treatment program' in the NORSOC's male-dominated Training Wing? We identified differences in the context that could be grouped into five themes, that we will now present.

First, the NORSOC personnel valued diversity and had the opinion that gender matters, while the ANCOCS personnel valued uniformity and claimed that gender did not matter. This difference was again linked to a different view on fairness and operational needs.

In the book Uniformity or Diversity (Edström et al. 2010), it is argued that uniformity (likeness) is important in the military context and that this can be justified by the operational need for functionality. Diversity, especially when it comes to women, should according to the authors be related to political ideas and requests for representation in 'safe societies of surplus', where it is possible to ignore the operational need for functionality.

At the ANCOS, we find, in line with the uniformity argument, a sense of justice and fairness which implies that everyone must be treated alike and, not least, that they must be selected for training through equal tests with equal demands, regardless of the type of education, or the function and role afterwards. This was evident in the exis- tence of a joint selection process for all NCO schools and branches of training within them. Several seemed to think that 'the best' for all purposes was he (or she) who was best able to carry a heavy backpack over long distances, or who performed best in the obstacle and mud course. This was because 'a soldier is a soldier' and everybody had to 'be potatoes', able to rotate to all functions. Moreover, everybody had to be ready to meet the 'demands of war', which were often related to obstacles and mud courses, exemplified by the fact that exercises in the obstacle and mud course were termed and spoken of as 'demands of war-test/exercises'.

Since the aim was to select 'the best' (for no particular task or job), it was claimed that gender didn't matter:

I do not care if it's a man or woman; I want the best, bottom line

(Officer at Joint Selection, Rones 2015, 215).

Several women also insisted that their gender was irrelevant, denying that they had been given access to training or positions because they were women.

In NORSOC, we find a different context. The idea of the all-female platoon resulted from an operational need for women for special operations where gender matters, e.g. house-search, body-search and interrogation in gender-segregated societies, reconnaissance and other unconventional tasks in populated areas. That means that NORSOC needed women because they were women, and as such it can be argued that the initiative relied on an assumption that men and women are essentially different (a gender difference approach, see Kristiansen 2017 for why women are needed for special operations in particular, and Solhjell 2013 and Persson 2013 for more detailed discussion of the quest for women to enter international military service).

Interestingly, in this war-experienced 
unit, it is a diversity perspective that is justified by an operational need for functionality. Uniformity/likeness and the idea that everyone should be able to rotate to do any task was, in contrast to ANCOCS, viewed as an ideology that hampered the opportunity to take advantage of complementary specialties and traits, including visual diversity, such as gender, ethnicity and skin color:

As long as you think everyone is equal, everyone has equal opportunities and everyone can be used for the same tasks, you are not able to take advantage of people's different qualities $[\ldots]$ If it is not allowed to say that: "You should not go first [in the door in an operation] because you are petite and female, instead we are going to have you in the back of the queue, because we want you to talk to women we have taken control of " - if that is discrimination and you cannot say it, so you have to rotate so she is allowed to go first in the door sometimes, then you can just skip everything and go back home (Leader/Instructor in NORSOCs Training Wing, Rones and Steder 2017, 30).

Based on such statements, it can be argued that NORSOC abandons the principle of likeness and uniformity in favor of a diversity and specialization perspective, where different types of people are selected for different tasks. This point of departure justified different treatment (equity) and different regimes for selection and assessment of the women. The NORSOC officers said that there was no operational reason that women should be able to carry heavy backpacks at the same pace as the strongest man, or be the fittest men's equals in the obstacle course. If the goal had been to get hold of more people who could carry heavy stuff over long distances, they would have increased the number of positions in the regular training program instead. But the goal was to get hold of the most capable women because they were women, not the strongest person (pp. 55-56). Officers in NORSOC also criticized the mindset that everyone should be measured in relation to one ideal, which mentally excludes women, as exemplified in this quote:

I have seen that in the Army. They are very keen to measure everyone in relation to the ideal infantryman. That infantryman possesses some characteristics that do not connect with everyone. So, then the girls are mentally excluded already there. And they cannot quite see that the Armed Forces represent more than that $[\ldots]$ At that point, I think the Army fails a lot

(Officer/instructor in the all-female platoon, Rones and Steder 2015, 56).

The second contextual issue that may have contributed to the different relationship between the women in the two cases was that the ANCOCS and NORSOC women were selected on different criteria regarding behavior that is often classified as masculine and feminine. The ANCOCS offered leadership training through a selection process that in particular emphasized the ability to stand out as the energetic leader of the group. For instance, the informants said that the ANCOCS had admitted a lot of 'strong-willed', 'extremely extroverted women' who had 'strong competition instincts', so that all desired to be both 'the best' and the leader (Rones 2015, 196201). One might imagine how the performance of such dominant qualities results from a selection process in which a woman not only must enter a male-dominated environment, but must also convince the selection officers that she is able to stand out as the leader who takes command over the group of men. Until recently the ANCOCS has been the (only) gateway to permanent employment in the Norwegian Armed Forces. Thus, its premises for admission may have contributed to reinforcing the view of women as particularly quarrelsome. Display of dominance is usually not classi- 
fied as a feminine behavior, and this may have contributed to the women who had the desired ability to stand out as the leader and enforce their will on other people (see Rones 2015, 183 and 240-241) being interpreted as particularly 'difficult' and quarrelsome by those who had to submit and obey their orders.

In NORSOC, the all-female platoon offered a secret elite-soldier training through a rigorous selection process that favored cooperative skills and team-playing qualities. Several of the women in the all-female platoon said that they hadn't been interested in the Armed Forces before. One reason was because the options had either been the basic service they felt anyone could do (no demanding selection process required) or the ANCOCS. The ANCOCS had the attractive selection process they desired, but some of the women said that it wasn't an option for them because it was leadership education, and they did not like to 'stick out' the way a leader had to do (they were too shy). It can thus be argued that NORSOC opened up recruitment and selection of women on new premises that may have allowed for women to enter the military without having to take the role of commander. Shyness and willingness to cooperate (or subordinate) are often linked to femininity, and so these women may also have been interpreted as less 'quarrelsome' than those admitted on the ANCOCS leadership premises.

Third, the ANCOCS 'offered' the possibility of becoming one of the guys, while NORSOC offered the possibility of becoming one of the girls. This seemed to have attracted women with different desires regarding gender and group-belonging. For instance, many ANCOCS women said that they preferred to be with men, and seemed to have actively and purposely steered away from environments with many women, which they believed were characterized by intrigues and drama (Rones 2015, 271273):
Female NCO-Candidate: There is a big difference between [a combat]-service and medics - I wouldn't have done that!

I: Why not?

Female NCO-Candidate: First of all, because there are so many women there. It is the worst thing of all $[\ldots]$

I: Why is it the worst of all that there are so many women there?

Female NCO-Candidate: [...] It's so incredibly annoying to be with women. There's so much drama immediately. It is so much easier with the men. [...] I think that it has mostly something to do with me. I am very fond of attention, and I get jealous very quickly. I think it's okay to have all the guys to myself

(Rones 2015, 273).

Based on statement like this, it is possible to suggest that the Armed Forces' maledominance has offered a possibility for escape/an opportunity to women who, for different reasons, have challenges with other women, or may not want to belong to the category 'women'. However, many of the ANCOCS women struggled to be fully accepted as one of the guys. They argued that it was preferable to be the only woman because it made it easier to become 'one of the guys', since it was expected that they should hang out with the women as soon as there were more women (p. 203).

In contrast, several NORSOC women could not imagine themselves entering the military as the only woman among a bunch of men (Rones and Steder 2015, 81-82). The risk of being a lone woman was also a reason why some of the NORSOC women had not been interested in the military before the all-female platoon became an opportunity (Rones and Steder 2015, 81-82):

I do not think I would have thrived in a guys' environment, only guys and then me. - No. Being the only girl in a squad, I think that would have been challenging [...] I think I would have felt very lonely. 
(Soldiers in the all-female platoon, Rones and Steder 2017, 81)

Several successful and non-successful applicants said they had applied to the all-female platoon because they believed it would be great to be part of such an all-woman group, and find other women who shared their interest. Some even emphasized that the absence of men was an advantage (Rones and Steder 2015, 47).

It's fun to think that "yes!- Girls can do a lot of stuff and we are really good at what we do." We are not the [physically] strongest in everything, but it's insanely cool that we are a girl-gang. [...] I really want to have it this way. Zero guys! That's cool [laughs]

(Soldiers in the all-female platoon, Rones and Steder 2017, 48)

An important attraction value in the all-female platoon seems accordingly to be that it was primarily intended for women. This seems to have attracted women who had a positive attitude towards other women, and who were comfortable/or desired to belong with 'the girls'.

Moreover, since NORSOC need women because they are women, the leadership did not expect women to become one of the guys:

We want girls in the Armed Forces, but they do not have to become guys. Because then we would have just recruited guys

(Officer/instructor in the all-female platoon, Rones and Steder 2017, 81).

In this way, the NORSOC context did not require the women to distance themselves from their gender category, or do the symbolical 'change of gender' that is involved in becoming 'one of the guys'. Instead, NORSOC allowed women to combine the group-identities of female and military professional, i.e. two identities that traditionally have been constructed and imagined as incompatible opposites (see Rones 2015, 59-60, 62-63, 67; Titunik 2000). This may have hampered the tendency to 'self-group distancing' that was observed among the ANCOCS women.

A fourth factor that influenced the social relationships was that internal labor became distributed according to traditional gender roles in the gender-mixed ANCOCS case. This hampered both men and women from developing skills and full confidence in tasks where the opposite gender had the power to define the expected standard. Moreover, it triggered the women into withdrawing from male-dominated tasks with the feeling that they were 'in fact' inferior to the men. This, in turn, contributed to establishing experience-based anecdotes that 'confirmed' the traditional narrative that 'women have nothing to do in the Armed Forces' (see Rones, 2017). In this situation, some of the ANCOCS women blamed each other for low performance and lack of success. Moreover, they struggled for individual recognition among the men through self-imposed performance requirements, and by criticizing women who did not perform in accordance with the imposed standard, i.e. a classic queen bee response.

In contrast, the NORSOC's, gender-segregated approach provided the women with a space to develop skills and competence in the most male-dominated tasks, without being competed with, judged or overrun by men. The single-sex training also 'forced' the women to take the main responsibility for traditional male tasks, and so reinforce their skills acquisition. Thus, the women in NORSOC's all-female platoon acquired skills that enabled them to handle 'hard core' military tasks with confidence. This unobstructed skills development resulted in recognition from the NORSOC men, and contributed most likely to the above-mentioned sense of achievement. This is in line with King's (2013, 2015 ) findings that women can be respect- 
ed and accepted in the military's inner sanctum if they can perform their military role with competence and professionalism. From the newer research on cohesion (Ben-Ari et al. 2010; King 2013; 2015; 2017), it is also likely that the successful training and performance contributed to binding the NORSOC women together as a cohesive and mutual supportive women's team (the consequences of the gendered division of labor for the women and men's skill acquisition, and the men's relationship to the women at ANCOCS are further elaborated in Rones 2017).

However, at this point it is important to take note of King's (2015) findings that sometimes women can be denigrated precisely because they are highly able and, therefore, threatening to male soldiers. For instance, some of the women who had formed the first all-female platoon cohort experienced being perceived as cocky, swollen-headed, arrogant, and smarty-pants in their subsequent service in the conventional forces, as a result of their high standards and not least NORSOC's elite status that was visible from the symbols on their uniform. This leads us to the fifth and last contextual situation we identified: NORSOC provided the women with a unique elite status without threatening the NORSOC men's unique elite status. Meanwhile, at ANCOCS it seemed like both men and women experienced an identity-threat from being associated with women.

For instance, the female NCO-candidates in the Medical Battalion had experienced more harassment and discrimination from their male peers than they did from male candidates in other battalions where there were only a few women. The women believed this was a result of a tendency to assign most women to the Medical Battalion (i.e. a service whose tasks and expertise was classified as feminine), thus reinforcing the battalion's already poor status as the "girly battalion" (Rones 2015, 280). The men in the Medical Battalion had had the experience that men from other services saw the medical service as less physically demanding, and thus suitable for women, and that they looked upon them as "puny", "wimps" and "nurses in uniform" (Rones $2015,276-284)$. It is likely that these men's harassment of the women was amplified by a need to reconstruct their self-image as masculine in a context in which the battalion and service they were associated with was classified as feminine. This classification had the following consequence, as expressed by one of the male candidates: "But it is also that we are seen as a gang of girls, and that we are all just girls in the Medical Battalion" (Rones 2015, 282). This illustrates how the men's identity and desire to be 'one of the guys' (claim of masculine status) was threatened by a high proportion of women; suddenly, the men were seen as one of the girls, and that seemed to create a need in the men in the Medical Battalion to get rid of the women (Rones 2017, 207, 303). This finding is in line with research that has shown that an increased share of women can arouse fear and scepticism among men and accordingly increase gender discrimination instead of diminishing it, as suggested by Kanter's theory of critical mass (see e.g. Yoder 1991). According to Derks et al.'s (2016; $2011 \mathrm{a} ; 2011 \mathrm{~b})$ queen bee theory, the queen bee behavior is encouraged by the identity-threat the women experience when they enter a unit in which their gender has a low reputation and status, and this finding shows that the women's status can be influenced by identity-threats experienced by the men.

In the NORSOC case, on the other hand, the women did not challenge the men's attractive elite status as 'the best men', or 'the selected few', and there was no question of them having the high physical fitness level required of these men. On the contrary, the need to establish a dedicated platoon for women served to confirm the assumption that no women would be 
able to manage the physical hardship required to be part of the regular training program in the Parachute Ranger Platoon (Rones 2017, 22-23).

Women are allowed to apply to the Parachute Ranger Platoon. But nobody can do it. It gets too heavy $[\ldots]$. They do not have a chance, it will become too heavy (Male soldier in the Parachute Ranger Platoon, Rones 2017, 23).

Moreover, the women in the all-female platoon had not been selected to beat the men or become the men's equal in the most 'identity-defining' task. "If we had needed more people to carry a heavy backpack over a mountain plateau, we would have taken in more men" (Rones 2017, 22), said one of the leaders. Accordingly, it could be expected that the all-female platoon would be seen as a B-team, compared to the Parachute Ranger Platoon. However, it appeared that NORSOC had succeeded in creating a sense of equal status and value (equivalency) among the women and men in the two single-sex platoons. The feeling of equal status was for instance expressed by a male paratrooper who said that he saw the two single-sex platoons as "two Ateams". The all-female platoon selected the best on women's physical premises. The regular training program selected the best on men's physical premises. The view of the two platoons as two A-teams seemed, however, to result from several conscious and 'pedagogical' decisions from the NORSOC leadership. Important for the women's feeling of equality in this regard was the equal allocation of resources in the form of equipment, training arenas, and skilled instructors (Rones 2017, 23; Rones and Steder 2017, 59-61).

Despite the fact that the NORSOC women had been admitted on a 'special treatment' program, it does not seem that the NORSOC women suffered under the constant suspicion that they were admitted unfairly under affirmative action, as has been reported from women at the $\mathrm{AN}$ COCS and in the Armed Forces in general (Eide et al. 2014, 53-55). On the contrary, it appeared that NORSOC had managed to establish a pragmatic approach to the selection criteria, where the intended work-requirements and tasks (i.e. diversity and specialization) were more important than being selected as the strongest or physically fittest person (uniformity). However, several actors in NORSOC said that they had to defend the NORSOC women's position to outsiders, who argued that the females had been admitted and prioritized for Special Forces training at the cost of 'better men'. This means that the recognition provided for the NORSOC women only existed inside NORSOC. The reports from the first NORSOC women under service in the conventional forces, who said they were being perceived as cocky, smarty-pants, indicated that they met some of the same challenges as the ANCOCS women when they left NORSOC: i.e. a tendency to be 'jacked down' if showing signs of 'superiority'. For instance, at ANCOCS several women had been told that they had no reason to brag or be proud of being selected, since allegedly all interested women had been admitted on a quota for political reasons.

The constant suspicion that they were admitted under affirmative action (see also Eide et al. 2014, 53-55), and accordingly had not had to prove themselves fit for 'the demands of war' was an important context for the ANCOCS women in particular. This seemed to contribute severely to the classical queen bee behavior where the ANCOCS women imposed strong and sometimes unreasonable performance demands on their female peers and subordinates. It was also an important reason why they fiercely opposed any form of special treatment, and required both themselves and other women to prove themselves at a sufficiently high standard (Rones 2015, 210220). Due to this context, many women 
got annoyed at other women who did not deliver in accordance with the expected standards. Young NCOs and candidates said for example; "I hate women who are not able to carry their own backpack" and "who are not physically fit" (Rones 2015, 201-202). Older female officers/NCOs said that they had done the same when younger in the interest of the image of women as a group, clearly drawing attention to how the other women's performance had threatened their own identity. However, the women's tendency to set performance and behavior requirements for the other women was an underlying cause of the so-called 'cat fight' observed among the ANCOCS women. This was exemplified in their accusation of the other women as being both too competitive and ambitious, and not ambitious enough. An officer also identified the most 'ambitious' women's tendency to engage in the more 'relaxed' women's performance as a direct cause of conflict between two 'girl-gangs':

There have been conflicts, [among the women] because some of the candidates aim very high, make high demands, want much more, they are more ambitious than the other candidates are, and not all the candidates are happy with that

(Instructor at ANCOCS, Rones 2015, 200).

So, in sum, these factors may have contributed to making the myth of the quarrelsome women come 'true', as was partly mentioned by one of the female NCO-candidates:

I have tried to discuss it with the girls [the tense situation among the women in the platoon]. If we are not even able to say 'good morning' when we meet for breakfast, we run right into that 'girls will always argue' thing (Female NCO-candidate, quote from Rones' 2015 dataset).

\section{Conclusion}

This article started by asking the question: why have military personnel, in particular military women, claimed that women are often so hostile towards each other that that it is preferable to keep them few in number and mixed with men 24/7? The NORSOC case showed us that women are able to cooperate harmoniously in an all-female situation, even when they are admitted on a 'special treatment' program into a heavily male-dominated unit. It is therefore argued that women's alleged tendency towards gossiping, drama and conflict-making is a myth that is made 'true' by 'queen bee behavior'. With reference to Bourdieu, we have interpreted queen bee behavior as an act of recognition whereby women comply with misogynist gender stereotypes and evaluate women negatively but set themselves apart from the category/group of women as someone who fits better with the guys. Moreover, we have claimed that this paradoxical submission to masculine domination can be seen as a performance of complicit masculinity in Connell's sketch of a gender hierarchy.

With inspiration from organizational psychologists who have argued that 'queen bee behavior' can best be understood as a response to the socio-contextual situation the women have entered (Derks et al. 2011b; 2016) we compared the harmonious NORSOC case with the 'conflict riddled' ANCOCS case, to see if we could identify contextual issues which could have hampered queen bee behavior in NORSOC and encouraged it at ANCOCS. Increased knowledge on why queen bee behavior occurs is important, because misogynist views expressed by women contribute to a powerful legitimization of continued discrimination against women.

The contextual examination indicated that queen bee behavior observed at ANCOCS could have been encouraged as a result of the combination of several factors: an ideology of uniformity and 'generalist 
skills', a view on fairness as equal treatment, the expectation that women should fit seamlessly in as one of the guys and the claim that gender doesn't matter even though the man and masculinity was the norm and the ideal. In this situation, both men and women experienced an identitythreat from being associated with the category 'women', and as such the women were 'forced' to distance themselves from their own social-identity group by doing a symbolical 'change of gender'.

In contrast to this, the article has shown how NORSOC needed women for special operations where the soldier's gender matters and applied an ideology of diversity and specialist skills. That resulted in a pragmatic approach to selection and assessment, with a view of fairness as equity (different treatment) and equivalency (equal value). Nor was it expected that the women should 'become one of the guys', or assimilate to masculine norms, standards and expression (style/humor). Accordingly, these women were not 'forced' to choose between their gender (group identity/category) and a professional/military identity. Combined with a pedagogical focus on the female's skill development and a single-sex organization that made any gendered division of internal labor impossible, NORSOC provided the women with an unobstructed and unhampered opportunity to develop skills usually reserved for men. That enabled the women to succeed and perform as professionals in hard-core military activities, something which bound the women together as a self-confident 'women's team' instead of setting them up so that they were 'forced' to distance themselves from the category 'women'.

\section{Notes}

1. The empirical material was gathered through multi-sited ethnographic fieldwork, containing 72 days of participant observation conducted at joint training and in-service specialization in the Armored Battalion and the Medical Battalion, as well as 65 interviews, of which 32 were with women.

2. The empirical material was gathered as a result of the Norwegian Defence Research Establishment being assigned to contribute an external evaluation of NORSOC's all-female training programme. In this regard we applied an ethnographic approach. First, Steder conducted 8 days of observation and 13 interviews from the first cohort of women (2014-2015). Then Rones followed the second cohort (2015-2016), doing 28 days of observation and recording 64 interviews. All females belonging to this cohort were interviewed twice, 7 female alumni from the first cohort were interviewed after 8-10 months in continued service, 11 males in the regular training program were interviewed at the end of the program, and different leaders and instructors were interviewed throughout the year. The observation and interview guides contained several of the same topics and questions as used in the foregoing ANCOCS study.

\section{REFERENCES}

- Ben-Ari, E., Lerer, Z., Ben-Shalom, U. and Vainer, A. 2010. Rethinking Contemporary Warfare: A Sociological View of the Second Al-Aqsa Intifada.

New York: State University of New York Press. - Bjerke, T.A. and Rones, N. 2017. The Fine Line between Funny and Offensive Humour in a Total Institution: An Ethnographic Study of Joking Relationships among Army Soldiers. Res Militaris. $7(2)$.

Bourdieu, P. 1998. Masculine Domination. Stanford, CA: Stanford University Press.

- Bourdieu, P. and Wacquant, L.J. 1992. An Invitation to Reflexive Sociology. Chicago: The University of Chicago Press.

- Charmaz, C. 2006. Constructing Grounded Theory. A Practical Guide Through Qualitative Analysis. London: Sage Publications.

. Connell, R. 2005. Masculinities. Sydney: Polity.

- Derks, B., Ellemers, N., Van Laar, C. and Groot, K. 2011 b. Do Sexist Organizational Cultures Create the Queen Bee? British Journal of Social Psychology. 50, 519-535.

- Derks, B., Van Laar, C. and Ellemers, N. 2016. The Queen Bee Phenomenon: Why Women Lead- 
ers Distance Themselves from Junior Women. The Leadership Quarterly. 27(3), 456-469.

- Derks, B., Van Laar, C., Ellemers, N. and Groot, K. 2011 a. Gender-Bias Primes Elicit Queen-Bee Responses Among Senior Policewomen. Psychological Science. 22(10), 1243-1249.

. Edström, H., Lunde, N.T. and Matlary, J.H. 2010. Uniformitet eller mangfold? Norsk militerprofesjon $i$ endring. Oslo: Abstrakt forlag.

- Eide, T.H., Lauritzen, T., Olsvik, V.M. and Stokke, M. 2014. Idealer og virkelighet-Mangfold $i$ Forsvaret, Sluttrapport fra prosjektet Rekruttering, sosialisering og militær kjernekompetanse i Forsvaret, 2011-2014, ØF-rapport 14/2014.

Lillehammer: Østlandsforskning.

- Ellemers, N. 2001. Individual Upward Mobility and the Perceived Legitimacy of Intergroup Relations. In: Jost, J.T. and Major, B. eds. The Psychology of Legitimacy: Emerging Perspectives on Ideology, Justice, and Intergroup Relations. New York: Cambridge University Press, 205-222.

- Ellingsen, D. and Lilleaas. U.B. 2017. Gender Equality in the Norwegian Armed Forces. ABMmedia AS.

- Enloe, C.H. 2000. Maneuvers. The International Politics of Militarizing Women's Lives. Berkeley, CA: University of California Press.

- Hellum, N. 2016. «Ikke ha fokus på om det er tut eller hank». En studie av jevn kjonnsfordeling blant menige i Luftvernbataljonen på Ørland. FFI-rapport 16/01923. Kjeller: Forsvarets forskningsinstitutt.

- Hellum, N. 2014. "Sminkedritt over hele vasken" - en kvalitativ feltstudie av kjønnsblandede rom og maskulinitetskultur i Forsvaret. FFI-rapport 14/02156. Kjeller: Forsvarets

forskningsinstitutt.King, A. 2017. Gender and Close Combat Roles. In: Woodward, R. and Duncanson, C. eds. The Palgrave International Handbook of Gender and the Military. London: Palgrave Macmillan, 305-318.

- King, A. 2015. Women Warriors: Female Accession to Ground Combat. Armed Forces \& Society. 41(2), 379-387.

- King, A. 2013. The Combat Soldier: Infantry Tactics and Cohesion in the Twentieth and Twenty-First Centuries. Oxford: Oxford University Press.

- Kristiansen, M. 2017. Women: A NATO Special Operations Forces Force Multiplier. Small Wars Journal, May 17, 2017.

- Kronsell, A. 2012. Gender, Sex and the Postnational Defense. Oxford: Oxford University Press.
- Lilleaas, U.-B. and Ellingsen, D. 2014. Likestilling i Forsvaret. Fortropp, baktropp og kamparena. Kristiansand: Oxford Research.

- Mackenzie, M. 2015. Beyond the Band of Brothers: The US Military and the Myth That Women Can't Fight. Cambridge, UK: Cambridge University Press.

- Persson, A. 2013. Gendered Military Divisions Doing Peacekeeping as Part of the Postnational Defence. Kvinder, Køn og Forskning. 2, 30-45. - RAND. 2010. Sexual Orientation and US Military Personnel Policy. An Update of RAND's 1993 Study. RAND Corporation.

Rones, N. 2017. Gender-Mixed Army Dorm Rooms, 50\% Women and All-Female Special Forces Training: How Does Norway's Radical Attempt to Integrate Women in the Military Work? Res Militaris. 7(2).

- Rones, N. 2015. The Struggle over Military Identity - A Multi-Sited Ethnography on Gender, Fitness and 'The Right Attitudes' in the Military Profession/Field. PhD Dissertation, Norges idrettshøgskole.

- Rones, N. and Steder, F.B. 2017. "Herregud, skal troppen ha bare jenter?” - En evaluering av Forsvarets spesialkommandos jegertropp for kvinner. FFI-rapport 17/16485. Kjeller: Forsvarets forskningsinstitutt.

- Ryan, W. 2010. What Were They Thinking?

Samuel A. Stouffer and the American Soldier. PhD Dissertation, University of Kansas.

- Simons, A. 2014. Here's Why Women in Combat Units is a Bad Idea. War on the rocks, November 18, 2014.

- Simons, A. 2000. Women Can Never 'Belong' in Combat. Orbis 44(3), 452-461.

Solhjell, R. 2013. Gendered Military Operations? Military Missions in Afghanistan and The Democratic Republic of Congo. Kvinder, Køn og Forskning. 2, 48-62.

- Staines, G., Tavris, C. and Jayaratne, T.E. 1974. The Queen Bee Syndrome. Psychology Today. 7, 55-60.

- Titunik, R.F. 2000. The First Wave: Gender Integration and Military Culture. Armed Forces \& Society. 26(2), 229-257.

- Ulriksen, S. 2002. Den norske forsvarstradisjonen. Militermakt eller folkeforsvar? Oslo: Pax Forlag. - Yoder, Janice D. 1991. Rethinking Tokenism. Looking beyond Numbers. Gender \& Society, 5, 178-192. 